\title{
Asymptomatic lingual tonsillar hypertrophy and difficult airway management: a report of three
}

\section{cases}

[Hypertrophie asymptomatique de l'amygdale linguale et intubation difficile: compte rendu de trois observations]

Sharon Davies MD FRCPC, Chidambaram Ananthanarayan MD FRCPC, Carmencita Castro MD FRCPC

Purpose: To report on the airway management of three cases of asymptomatic lingual tonsillar hypertrophy (LTH).

Material: On three separate occasions, patients presenting for elective surgery were subsequently found to have asymptomatic LTH. In all cases preoperative airway examination was essentially unremarkable and no unusual difficulties were anticipated. In the first case, despite an inability to visualize the glottic opening, the patient was intubated successfully on the initial attempt and had no further problems in the perioperative period. In the second case, neither direct laryngoscopy, utilizing the Maclntosh and McCoy blades, nor fibreoptic visualization enabled successful intubation. Ventilation was maintained with a laryngeal mask airway (LMA) until the anesthetic was reversible. Upon awakening and removal of the LMA, the patient totally obstructed and could not be ventilated, necessitating emergency cricothyroidotomy. The third patient was an elderly gentleman in whom successful intubation was eventually achieved, with considerable difficulty, by the otorhinolaryngologist (ENT surgeon) utilizing a straight blade. On a second occasion, he was again intubated by the same ENT surgeon, this time utilizing the anterior commissure blade. All three patients were subsequently discharged without further sequelae.

Conclusion: Asymptomatic LTH can cause varying degrees of unexpected difficulty in securing the airway and, at present, no single method will necessarily improve the chances of successful intubation. Therefore, strategies to manage unanticipated difficult intubation secondary to supraglottic airway pathology need to be performed and practiced, including the establishment of a transtracheal airway.

Objectif: Faire état de la prise en charge de trois cas d'hypertrophie asymptomatique de l'amygdale linguale (HAL).

Éléments cliniques : En trois occasions différentes, des patients opérés en chirurgie élective ont reçu ultérieurement un diagnostic d'HAL. Dans les trois cas, l'examen préopératoire des voies aériennes n'a présenté aucune particularité et aucune difficulté inhabituelle n'a été envisagée. Dans le premier cas, malgré l'impossibilité de visualiser l'ouverture glottique, le patient a été intubé avec succès au premier essai et n'a présenté aucun problème périopératoire. Dans le deuxième cas, ni la laryngoscopie directe, à l'aide de lames Maclntosh et McCoy, ni la visualisation fibroscopique n'ont permis l'intubation. La ventilation a été maintenue avec un masque laryngé (ML) jusqu'au renversement de l'action anesthésique. Au réveil, et au retrait du ML, les voies aériennes étaient complètement obstruées et la ventilation était impossible, ce qui a exigé une crico-thyroïdotomie. Le troisième patient était un monsieur âgé chez qui l'intubation a finalement été réussie, très difficilement, par un oto-rhino-laryngologiste (ORL) avec une lame droite. Lors d'une seconde intervention, il a été encore intubé par le même chirurgien ORL qui a utilisé, cette fois, une lame pour la commissure antérieure. Les trois patients ont reçu leur congé par la suite et n'ont subi aucune séquelle.

Conclusion : Une HAL asymptomatique peut entraîner diverses difficultés inattendues d'intubation. Actuellement, aucune méthode particulière ne peut améliorer les chances de réussite de l'intubation. En conséquence, les stratégies visant à intuber malgré des difficultés imprévues secondaires à une pathologie supraglottique doivent être expérimentées et répétées, sans oublier d'assurer la perméabilité des voies aériennes transtrachéales.

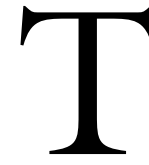

HE lingual tonsil, a normal component of Waldeyer's ring, consists of lymphoid tissue located at the base of the tongue. Acute inflammation and hypertrophy can occur and has been reported to be one of the unusual causes

From the Department of Anesthesia, University of Toronto, Mount Sinai Hospital, Toronto, Ontario, Canada. 
of unexpected difficulties with both mask ventilation and tracheal intubation. ${ }^{1-3}$ We present three cases of asymptomatic lingual tonsillar hypertrophy (LTH), each requiring different clinical interventions to secure the airway, including emergency cricothyroidotomy.

\section{Case 1}

An otherwise healthy $40 \mathrm{yr}$ old woman was scheduled for abdominal hysterectomy. General physical examination was unremarkable including upper airway examination which revealed a Mallampati I score with normal mouth opening and neck mobility. She consented to participate in a study on pre-emptive analgesia involving combined epidural and general anesthesia. An iv infusion was established and the epidural catheter inserted without incident.

Following placement of routine monitoring and preoxygenation, anesthesia was induced with $150 \mu \mathrm{g}$ of fentanyl, $150 \mathrm{mg}$ propofol combined with $20 \mathrm{mg}$ lidocaine and $50 \mathrm{mg}$ rocuronium. Laryngoscopy revealed a Grade III Cormack Lehane view. Cricoid pressure was applied to push the larynx posteriorly, following which the trachea was intubated successfully. However, despite successful intubation, the anesthesiologist was unable to visualize the glottic opening adequately due to the presence of pale white tissue in the vallecula. Direct laryngoscopy and fibreoptic endoscopy were performed by an otorhinolaryngologist (ENT surgeon) who made the diagnosis of LTH. Following completion of the surgery, the muscle relaxation was reversed and the patient was extubated without incident. Her subsequent course was uneventful and she was discharged home four days later. She was given a letter regarding the abnormality and was advised to see the ENT surgeon for follow-up.

\section{Case 2}

Due to an earlier delay in the operating room schedule, a 51-yr-old man was brought to the operating room at 21:00 hr for an elective excision of a pilonidal sinus in the prone position. His past medical history was unremarkable except for a cholecystectomy and degenerative lumbar disc disease. He smoked approximately $1^{1} \frac{1}{2}$ packages of cigarettes a day. His only medication was Arthrotec. Physical examination revealed a moderately obese gentleman who weighed $100 \mathrm{~kg}$ and was $178 \mathrm{~cm}$ tall. Clinical assessment of the airway was felt to be well with in normal limits and no difficulties were anticipated. Specifically, he had a class II Mallampati airway, a thyromental distance greater than $6 \mathrm{~cm}$ and normal range of motion in his neck and temporomandibular joint.

Following placement of routine monitors and preoxygenation, anesthesia was induced using fentanyl 200 ug, propofol $200 \mathrm{mg}$ with $40 \mathrm{mg}$ lidocaine and rocuronium $50 \mathrm{mg}$. Using a \#3 Macintosh blade, direct laryngoscopy revealed redundant pharyngeal tissue and partial visualization of the epiglottis which appeared to be displaced posteriorly against the wall of the pharynx, totally obscuring the glottic opening (Cormack Lehane Grade III). A \#4 Macintosh blade failed to improve the view due to an inability to elevate the epiglottis. A \#4 laryngeal mask was inserted while the difficult intubation cart and respiratory therapist were summoned. Once both were present, direct laryngoscopy was repeated using the \#4 McCoy articulating blade. This also proved to be unsuccessful in facilitating intubation. The LMA was therefore reinserted and assistance from a second anesthesiologist (in hospital) was sought. A decision was made to proceed to oral, flexible fibreoptic laryngoscopy. This was chosen as the method least likely to traumatize the airway and one which both anesthesiologists were familiar with. However, cognizant of the need to limit airway manipulation, both attempts as fibreoptic intubation were brief and quickly aborted due to similar difficulties with redundant tissue interfering with visualization of the larynx. The LMA was reinserted and a decision was made to awaken the patient. While waiting for the patient to awaken, ventilation through the LMA became increasingly difficult, but was considered adequate with $\mathrm{SPO}_{2}$ remaining at 98\%. After monitoring neuromuscular blockade, muscle relaxation was reversed and the patient allowed to emerge from the anesthetic. Upon awakening, the LMA was removed. Immediately thereafter the patient began to struggle and, very rapidly, became cyanotic with a precipitous fall in oxygen saturation and loss of consciousness. Two-person mask ventilation with an oral airway was impossible. The extreme urgency of the situation was evident and a brief attempt at needle cricothyroidotomy was unsuccessful. This was followed by an emergency cricothyroidotomy by the attending anesthesiologist. A \#7.0 cuffed endotracheal tube (ETT) was inserted successfully through the tracheal incision with rapid improvement in the patient's oxygenation and stabilization of the vital signs. Anesthesia was again induced while the ENT resident was called. The cricothyroidotomy tube was then exchanged for a \#7.0 cuffed treacheostomy tube. No further interventions were deemed necessary at that time. Diagnostic rigid laryngoscopy was performed by the ENT resident who was able to confirm the difficulty in visualizing the glottis, "swollen tissue", and edema. The patient was awakened, responded appropriately and taken to the recovery room in good condition.

The following day a decision was made to convert the cricothyroidotomy to a conventional tracheostomy. At 
this time, the attending anesthesiologist elected to perform a fibreoptic examination of the upper airway. Despite expert assistance and a controlled situation, observers noted this to be unusually difficult to perform, despite the considerable experience and expertise of the anesthesiologist. Once the airway was visualized it became clear the "swollen tissue" previously noted represented markedly hypertrophied lingual tonsils, accounting for the previous difficulty with intubation. Approximately three weeks later, fibreoptic examination of the airway under local anesthesia was easily performed by the initial attending anesthesiologist. The lingual tonsils were now barely visible and all airway structures appeared normal. At the same time clinical assessment by independent observers confirmed the lack of any clinical indices suggesting a difficult intubation. The patient made a full recovery without sequelae. He was advised to wear a medical alert bracelet and has a letter discussing the previous difficulties with intubation.

\section{Case 3}

A 73 yr-old-man was scheduled for grafting of bilateral iliac artery aneurysms. His history included hypertension, presently well controlled on nifedipine, and an uneventful hemorrhoidectomy under general anesthesia. Examination of the airway was normal except for a Mallampati II score and a small chin. Following preoperative assessment, he agreed to a combined epidural and general anesthesia.

Prior to induction, a thoracic epidural was inserted and routine monitors were applied. This was followed by $i v$ induction of general anesthesia using fentanyl, propofol and rocuronium. Manual ventilation was easy. At direct laryngoscopy, using a \#3 MacIntosh blade, a friable mass was noted in the vallecular area. The epiglottis was immobile and its tip directed posteriorly. Two \#4 blades, a curved MacIntosh and a straight Miller, were utilized but intubation was unsuccessful. An ENT surgeon was called. Attempts at fibreoptic intubation by the anesthesiologist and the ENT surgeon were unsuccessful due to difficulty directing the tip of the fibreoptic endoscope under the epiglottis. The surgeon then elected to insert the straight blade into the extreme right side of the mouth and, in a manner similar to rigid bronchoscopy, was able to blindly insert a bougie into the trachea. The \#7 ETT was then successfully threaded over it. Intraoperatively, nasopharyngoscopy was performed and revealed round lymphoid tissue arising from the vallecula, covering both the epiglottis and part of the ETT. Two hours postoperatively the patient was extubated in the recovery room without incident.

Following hospital discharge, the patient was reassessed by ENT. A computed tomography scan

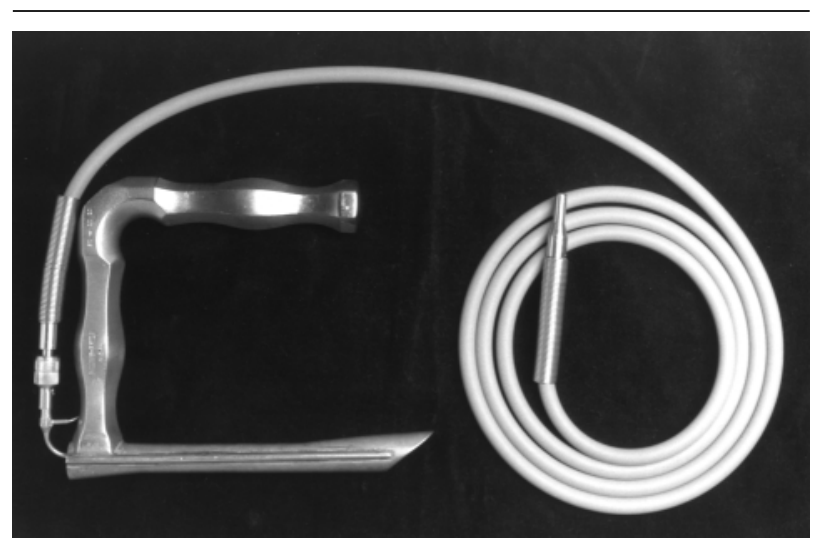

FIGURE

showed prominent lymphoid tissue at the left tongue base, appearing slightly irregular in the region of the vallecula. There was thickening of the midline glossoepiglottic fold but the epiglottis itself was unremarkable. A subsequent biopsy under general anesthesia revealed normal lymphoid tissue, consistent with lingual tonsil. At this time, asleep intubation was performed by the ENT surgeon utilizing an anterior commissure blade and tube exchanger (Figure). The attending anesthesiologist felt that the induction of anesthesia was appropriate as the patient had previously been easy to ventilate. As well, the same ENT surgeon was present and ready to intervene if difficulties were once again encountered.

\section{Discussion}

The term lingual tonsil refers to a discrete mass of lymphoid tissue located at the base of the tongue. ${ }^{2}$ Although there is considerable variation in the size and disposition of this tissue, when enlarged, one most commonly sees two lateral masses symmetrically placed on either side of the midline. These are divided by the glosso-epiglottic fold and may become so prominent that they fill the vallecula and displace the epiglottis posteriorly. ${ }^{4}$ The lymphatic drainage pattern is similar to that of the supraglottic larynx, resulting in the lack of a significant anatomic "barrier" between these two structures. ${ }^{5}$ This in turn may allow contiguous spread of infection or edema between the epiglottis and the lingual tonsils. In our second case there was a significant amount of edema in the posterior pharynx and related structures.

Hypertrophy of the lingual tonsil has occasionally been reported in children ${ }^{3}$ but most often occurs in 
adults, particularly in atopic individuals. ${ }^{4}$ The etiology is presently unclear. However it is speculated to be a compensatory mechanism following removal of the palatine tonsils ${ }^{6}$ or secondary to a chronic, low-grade infection of the tonsils. ${ }^{4}$

Clinically, LTH is not detectable on routine preoperative physical examination. ${ }^{1}$ Although many patients are asymptomatic, others may complain of a globus sensation, alteration of voice, chronic cough, choking or dypsnea., ${ }^{4,7}$ Acute inflammation is characterized by sore throat, cough, dysphagia, fever and leukocytosis. ${ }^{4}$ Associated complications include airway obstruction, infection, abscess formation, obstructive sleep apnea and recurrent adult epiglottitis. ${ }^{5,8-10}$

Treatment is directed towards the avoidance of excessive throat clearing or other aggravating factors such as dusts, tobacco smoke or chemical irritants. ${ }^{4}$ Acute inflammation usually responds to analgesics, rest, appropriate antibiotic therapy and possibly steroids. ${ }^{4}$ Allen et al ${ }^{11}$ reported the successful use of parenteral epinephrine in a patient with impending airway obstruction secondary to acute lingual tonsillitis. Surgical treatment is rarely required and is generally reserved for patients with symptomatic airway obstruction, tonsillar abscess or recurrent infection unresponsive to antibiotic therapy. ${ }^{4,7}$

Unfortunately, since LTH is not detectable on history or physical examination, unexpected difficulties with mask ventilation and tracheal intubation will continue to occur. Jones and Cohle ${ }^{1}$ were the first to report a death secondary to failed airway management in a patient with unrecognized LTH. More recently Asai et al. ${ }^{2}$ reported a case of suboptimal ventilation and failed tracheal intubation using various intubation strategies including the intubating laryngeal mask and fibreoptic endoscope.

As noted previously, enlarged lingual tonsils can impinge against the epiglottis, displacing it posteriorly. This can make mobilization of the epiglottis difficult utilizing the usual laryngoscopic procedures Similarly, as seen in our second and third cases, asleep fibreoptic intubation is often equally difficult due to the posterior displacement of the epiglottis causing interference with the insertion of the tip of the endoscope under it. These difficulties may be compounded by the presence of redundant pharyngeal tissue interfering with fibreoptic exposure and the use of muscle relaxants. ${ }^{1}$ With the onset of neuromuscular blockade the pharyngeal musculature relaxes, causing further posterior movement of the tongue and epiglottis. ${ }^{12}$ In our third patient, at the time of his second surgery, the ENT surgeon utilized an anterior commissure blade for direct laryngoscopy. This may be a very useful tool for difficult cases and perhaps one with which anesthesiologists should become familiar.

More recently, anesthesiologists have become familiar with the use of LMA as an alternative strategy in the management of the unanticipated difficult airway. It can be particularly useful in re-establishing ventilation and oxygenation when other measures have failed. However, the case report by Asai et al. ${ }^{2}$ highlights the fact that the LMA cannot always solve a truly glottic or subglottic problem; rather, the ventilatory mechanism must get below the lesion. ${ }^{13}$ The authors further cautioned that the insertion of the LMA and subsequent intubation through the LMA are both blind techniques that can, potentially, damage pathological tissue near the laryngeal inlet. ${ }^{2,14}$ They suggest that in emergency situations preparation for a transtracheal airway be made during attempts at placement of the laryngeal mask, in the event that ventilation is inadequate. In our second case, it was speculated that insertion of the LMA between intubation attempts may have contributed to edema of the airway, despite a limited number of attempts at conventional laryngoscopy. In fact, the only difference in the management of the second and third cases was the use of the LMA between intubation attempts. Most practicing anesthesiologists have had cases where blood is noted on the LMA at removal, following what was thought to be an easy insertion. This suggests that the LMA may not be as atraumatic as commonly believed, particularly in the presence of airway pathology. Alternatively, it is possible that acute LTH, as seen in the second case, is more susceptible to edema than chronic. However, both explanations are speculative. What is most important is that our second case underscores the need for every anesthesiologist to be able to establish a transtracheal airway and to utilize this technique early in situations where nonsurgical methods have failed. It also serves as a reminder that in the "can't intubate, can't ventilate situation", significant arterial desaturation occurs very rapidly. In the unfortunate case described by Jones, ${ }^{1}$ although emergency tracheostomy was accomplished within five minutes of induction, the patient suffered irreversible brain anoxia.

The future anesthetic management of patients previously diagnosed as suffering from asymptomatic LTH is somewhat of a dilemma. Considering the dynamic nature of the hypertrophy, as demonstrated in our second case as well as the report by Asai, et al., there may be no history of difficulties with previous intubations. Similarly, future intubations may not necessarily be difficult. However, since many of these patients are asymptomatic, we recommend a preoperative consultation with an ENT surgeon, prior to any 
elective anesthetics. Careful observation with a laryngeal mirror or nasopharyngoscopy will allow the surgeon to assess the base of the tongue. ${ }^{4}$ Lateral soft tissue $x$-rays are also valuable and correlate well with indirect examination. If LTH is still present or time does not permit this assessment, then an awake intubation is recommended. Although the method used to secure the airway must be left to the discretion of the attending anesthesiologist, we believe that, in the conscious patient, fibreoptic intubation is the least traumatic and the one most likely to be successful.

In summary, from our review of the literature and limited experience in the management of these cases, we would like practicing anesthesiologists to be aware of this condition and encourage a cautious approach to airway management. If LTH is known to be present, we suggest awake intubation as the most desirable method. Unfortunately, since many patients are asymptomatic, anesthesiologists will continue to experience unexpected difficulties with tracheal intubation. Under these circumstances, there is presently no single method of securing the airway that will increase the likelihood of success. Difficulties with both asleep fibreoptic intubation and intubating LMA have been reported and the establishment of a transtracheal airway may become necessary.

\section{References}

1 Jones $D H$, Coble $S D$. Unanticipated difficult airway secondary to lingual tonsillar hyperplasia. Anesth Analg 1993; 77: 1285-8.

2 Asai T, Hirose T, Shingu K. Failed tracheal intubation using a laryngoscope and intubating laryngeal mask. Can J Anesth 2000; 47: 325-8.

3 Guarisco JL, Littlewood SC, Butcher III RB. Severe upper airway obstruction in children secondary to lin gual tonsil hypertrophy. Ann Otol Rhinol Laryngol 1990; 99: 621-4.

4 Golding-Wood DG, Whittet $H B$. The lingual tonsil. A neglected symptomatic structure? J Laryngol Otol 1989; 103: 922-5.

5 Wilson JF, Coutras S, Tami TA. Recurrent adult acute eipglottis: the role of lingual tonsillectomy. Ann Otol Rhinol Laryngol 1989; 98: 602-4.

6 Jesberg $N$. Chronic, hypertrophic, lingual tonsillitis. Arch Otolarygol 1956; 64: 3-13.

7 Puar RK, Puar HS. Lingual tonsillitis. South Med J 1986; 79: 1126-8.

8 Dindzans LJ, Irvine BWH, Hayden RE. An unusual case of airway obstruction. J Otolaryngol 1984; 13 . $252-4$

9 Newman RK, Johnson JT. Abscess of the lingual tonsil. Arch Otolaryngol 1979; 105: 277-8.
10 Olsen KD, Sub KW, Staats BA. Surgically correctable causes of sleep apnea syndrome. Otolaryngol Head Neck Surg 1981; 89: 726-31.

11 Allen DM, Hall $K N$, Barkman $H W$. Lingual tonsillitis: an uncommon cause of airway compromise responsive to epinephrine (Letter). Am J Emerg Med 1991; 9 : $622-4$.

12 Crosby ET, Cooper RM, Douglas MJ, et al. The unantic ipated difficult airway with recommendations for management. Can J Anaesth 1998; 45: 757-76.

13 Benumof J. The ASA difficult airway algorithm: new thoughts/considerations. ASA Annual Refresher Course Lectures 1996; 211 : 1-7.

14 Asai T, Vaughan RS. Misuse of the laryngeal mask airway (Editorial). Anaesthesia 1994; 49: 467-9. 